\title{
Power Recovery in a Gas Pressure Reduction Station using 3D CFD Modeling of a Twin Screw Expander
}

\author{
H. Abolhasani, M. Moghimi ${ }^{\dagger}$ and M. Ebrahimi \\ School of Mechanical Engineering, Iran University Science and Technology, Tehran, Iran \\ †Corresponding Author Email: Moghimi@iust.ac.ir
}

(Received September 6, 2019; accepted December 14, 2019)

\begin{abstract}
The limitation of energy resources in the world has cut the attention of many researchers to find new resources of clean energy and develop methods for recovering exergy losses. Twin screw expander (TSE) is one of the positive displacement machines that has been widely applied in recent years to recover mechanical power from fluids due to its lower installation, operation, and maintenance costs in comparison with common expansion turbines (CET). In this paper, technical and economic conditions of a city gate station (CGS) were studied with the aim of recovering exergy loss using a TSE. A computational fluid dynamic code was used to simulate the three-dimensional fluid flow in the TSE. The simulation results for Shahroud station - a CGS located in the east of Iran - revealed that, unlike CET, flow and pressure fluctuations in different seasons of the year did not put any restrictions on the use of TSE whereby $85.3 \%$ of annual loss exergy was recovered. Economic studies showed that the internal rate of return (IRR) and payback period of TSE utilization were obtained of $27.6 \%$ and 4.4 years, respectively, making the investment in CGS stations more practical compared to the CET.
\end{abstract}

Keywords: Twin screw expander; City gate station; CFD; Exergy analysis.

\section{NOMENCLATURE}

A

Computational Fluid Dynamics

CGS City Gate Station

D male rotor outer diameter

h specific enthalpy

IRR Internal Rate of Return

$\mathrm{L} \quad$ rotor length

$\dot{m} \quad$ mass flow rate

$n \quad$ rotational speed

NG Natural Gas

$\mathrm{P} \quad$ pressure

PC Pressure Controller

PCV Pressure Control Valve

PSV Pressure Safety Valve

$r_{f} \quad$ female pitch circle radius

$r_{m} \quad$ male pitch circle radius

$\mathrm{T}$ temperature

$\begin{array}{ll}T & \text { torque } \\ t & \text { time } \\ \mathrm{t}_{\mathrm{c}} & \text { end angle of the arc BM-CM } \\ \mathrm{tf} & \text { end angle of the arc GM-FM } \\ \mathrm{t}_{\mathrm{g}} & \text { end angle of the arc HM-GM } \\ \mathrm{th}_{\mathrm{g}} & \text { end angle of the arc AM-HM } \\ \mathrm{TSE} & \text { Twin Screw Expander } \\ \mathrm{Z} & \text { Rotor number of lobes } \\ & \\ \eta_{g e n} & \text { generator efficiency } \\ \beta_{1} & \text { end angle of the arc AM-BM (Degree) } \\ \varepsilon_{2} & \text { pressure angle shown in Fig. 4 } \\ \eta_{g e a r} & \text { gearbox efficiency } \\ \eta_{E x} & \text { exergy efficiency } \\ \eta_{E X-D} & \text { design exergy efficiency } \\ \varphi & \text { rotational angle } \\ \boldsymbol{\psi} & \text { male rotor wrap angle }\end{array}$

\section{INTRODUCTION}

Over the past three decades, the demand for energy has been significantly boosted with increasing population and economic growth. Oil and gas play an important role in supplying the required energy in the world. The modern use of renewable energy in this field and the new technologies of exergy recovery are rapidly growing. Expansion turbines are one of the systems that have been considered for many 
years in electrical power generation. These ultravaluable devices can also be used to recover exergy loss at CGSs. So far, numerous papers have been published on the use of common expansion turbines at CGSs and gas expansion processes.

EI Hadik (1990) conducted a parametric study to assess the effects of ambient temperature, pressure, humidity, and inlet temperature on the turbine power and efficiency. He concluded that the variation in the gas temperature at the turbine inlet has the greatest effect on efficiency so that as the temperature increases at the turbine inlet, the efficiency is augmented as well. Pozivil (2004) reported the simulation results for a gas pressure reduction station, showing temperature drop in the choke valve and expansion turbine. Furthermore, based on the results, the gas temperature decreased by circa 15-20 ${ }^{\circ} \mathrm{C}$ for the pressure drop of $1 \mathrm{MPa}$. Rahman (2010) measured and studied the production capacity from the gas pressure drop by an expansion turbine for several gas wells and pressure reduction stations in Bangladesh. The results obtained from theoretical calculations were compared with operational results, revealing that pre-heating before the expansion is almost always necessary to avoid hydrate formation. Howard et al. (2011) examined factors affecting the replacement of choke valve with expansion turbine by studying a small CGS station in a city located in Canada. They showed that the efficiency of expansion turbine would increase by approximately $10 \%$ by adding a fuel cell to the gas expansion process. They also simulated the effect of gas flow rate on the electricity output and evaluated the economic profits. Taheri et al. (2010) studied Tehran CGS station and illustrated that the annual exergy of about $40 \mathrm{GWh}$ is lost annually in the expansion process by choke valves, which can be recovered up to $96 \%$ using the expansion turbine. Olfati et al.( 2018) studied the Bistoon station in Iran, showing that the highest exergy losses occur in winter. Zehtabiyan and Saffar (2012) studied a CGS station in Takestan, Iran, for the application of an expansion turbine to generate power. They showed that the flow rate fluctuations in different seasons alter the amount of electric power generated by the expander. Zabihi and Taghizadeh (2016) studied the Sari-Akand CGS station for recovering exergy loss in a choke valve. They revealed the annual energy loss of $7.1 \mathrm{GWh}$ can be reduced to $3.9 \mathrm{GWh}$ by using an expansion turbine where it is only operational for seven months due to flow rate fluctuations.

Despite various studies supporting the use of CET at CGS to recover exergy, there are some downsides for its application, namely high investment costs relative to its revenue, high maintenance and operation costs, and lack of economic justification for small and medium stations. Therefore, in order to use CET in CGS stations, one needs to consider improvements in the optimization process or replacement of other expansion turbines. A TSE can be a better alternative to CET at CGS stations, offering the advantages of lower capital, operation, and maintenance costs (Smith et al. 2005) and the ability to extract exergy from two-phase fluid (Graber and Brummer, 2015).

The first screw machines were introduced in 1952 and tremendous efforts have been put into manufacturing two-phase expansion turbines since the early 1970s. Some studies were performed in 1973 on using a screw expander for the expansion of the pressurized steam-water mixture as a tool to recover energy loss. The utilization of TSEs were supported by the oil crisis occurred in the 1970s to expand two-phase fluids. In 1976, efforts were put into modeling the screw turbines expansion process via the empirical correlations. Sangfors (1982) modeled the expansion process in a TSE using fairly plain techniques. Steidel et al. (1983) experimentally investigated a screw expander on a mixture of water and steam. Later, Smith (1993) started studying two-phase expansion processes provided by screw turbines as driving motors. It was revealed these expanders are not capable of fulfilling the high-pressure water expansion process (Smith et al. 1996). Smith et al. ( 1999) designed and manufactured a laboratory model of the screw expander operating with R-113 as the working fluid. This screw expander offered highly acceptable performance where the adiabatic efficiency had the maximum value of $76 \%$. Stosic et al. (2002) and Smith et al. (2005) performed the thermodynamic analysis of such machines by benefiting from a 1D thermodynamic model, showing that their expansion efficiency depends on several factors including size and shape of high-pressure port, leakage flows, and built-in volume ratio. Brummer and Hutker (2009) and Hutker and Brummer (2012) assessed the performance of screw expanders by examining length to diameter ratio, built-in volume ratio, and wrap angle. Also, Nikolov et al. ( 2012) examined the effect of rotor and body thermal deformation on the performance of such machines.

The performance of screw expanders has been investigated since 2013 by performing 3D CFD analyses. Kovacevic and Rane ( 2013) studied the clearance impact on the internal leakage and provided the accurate design of high-pressure port using CFD method for air as the working fluid, indicating that leakage flows pose a dominant effect on the efficiency of screw expanders. Papes et al. (2014) studied the effect of clearance gaps on the expander performance using CFD with R245fa as the working fluid. Andres et al. ( 2016) simulated a 3D CFD model and showed that internal leakage flows have the most crucial effect on the efficiency at low speeds and high inlet pressures. Domingues ( 2018) examined the benefits of using a TSE at CGS stations, showing that the TSE capability of withstanding two-phase flow fluctuations while maintaining a steady word delivery. Tian et al. (2017) studied a TSE under fluctuating operating conditions in a steam pipeline. Based on their results, increasing expander rotational speed has a negative effect on the isentropic efficiency. Diao et al. (2018) implemented the finite element analysis (FEA) technique and examined the rotor dynamics of a TSE. They generally reported that the TSE utilization is the most affordable, easiest, and most reliable way to recover exergy loss at CGS stations.

All of the previous studies on exergy recovery at the CGS stations have been based on zero- or one- 
dimensional analyses. In this case, the performance of an expander - regardless of its type - is obtained for different operating conditions with the assumption of an initial value for its isentropic efficiency. In this paper, a three-dimensional fluid analysis is carried out to investigate the operation of a TSE based on the field information available from Shahroud CGS. To the best of the authors' knowledge, this study considers practical data in CFD analysis for the first time. The proposed model is technically and economically reviewed based on the variable process conditions at this station.

\section{CFD Modeling}

In the CFD modeling, the Navier-Stokes differential equations are converted to algebraic equations by dividing the solution domain into computational cells and applying boundary conditions. A set of linear equations are then generated to be solved for all elements and several iterations so as to obtain an approximately accurate. In this study, a CFD model was used to simulate the three-dimensional fluid flow in the TSE. Achieving a reliable numerical solution for the TSE is a prerequisite for the simulation model which involves designing geometry, meshing, boundary conditions, as well as validation against experimental data.

\subsection{TSE Rotors Profile}

Using a primary curve on one rotor and conjugate motion to generate the concerned curve on the other rotor constitute the general technique to design the TSE rotor profile. In other words, a curve is firstly allocated to one of the rotors, and then the conjugate profile on the other rotor is obtained by using the envelope theory as the envelope of the chosen curve (see Fig. 1).

It is feasible to produce proper TSE profiles for various process conditions by applying the envelope theory and using an in-house developed code in FORTRAN on the basis of the flowchart presented in Fig. 2.

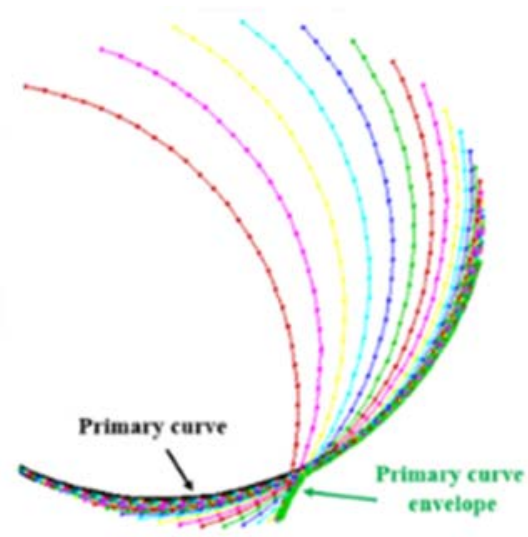

Fig. 1. Envelope theory.

Two coordinate systems are dedicated to each of the rotors (male and female) to design the TSE rotors. According to Fig. 3, $\mathrm{O}_{1} \mathrm{X}_{1} \mathrm{Y}_{1}$ and $\mathrm{O}_{2} \mathrm{X}_{2} \mathrm{Y}_{2}$ stand for the fixed coordinate systems with $\mathrm{O}_{1}$ and $\mathrm{O}_{2}$ as their origins, respectively, that coincide with the female/male rotor centers. The rotating coordinate systems are denoted by $\mathrm{O}_{1} \mathrm{x}_{1} \mathrm{y}_{1}$ and $\mathrm{O}_{2} \mathrm{x}_{2} \mathrm{y}_{2}$ that rotate with rotors (attached to rotors). At the rotation initiation, $\mathrm{O}_{1} \mathrm{X}_{1} \mathrm{Y}_{1}$ and $\mathrm{O}_{2} \mathrm{X}_{2} \mathrm{Y}_{2}$ coincide with $\mathrm{O}_{1} \mathrm{X}_{1} \mathrm{y}_{1}$ and $\mathrm{O}_{2} \mathrm{x}_{2} \mathrm{y}_{2}$, respectively. Then, $\mathrm{O}_{1} \mathrm{x}_{1} \mathrm{y}_{1}$ and $\mathrm{O}_{2} \mathrm{x}_{2} \mathrm{y}_{2}$ (the female and male coordinate systems, respectively) rotate clockwise and counterclockwise around the origins $\mathrm{O}_{1}$ and $\mathrm{O}_{2}$ with the angle of $\varphi_{1}$ and $\varphi_{2}$ according to the constant ratio of angular velocity between the rotors, respectively.

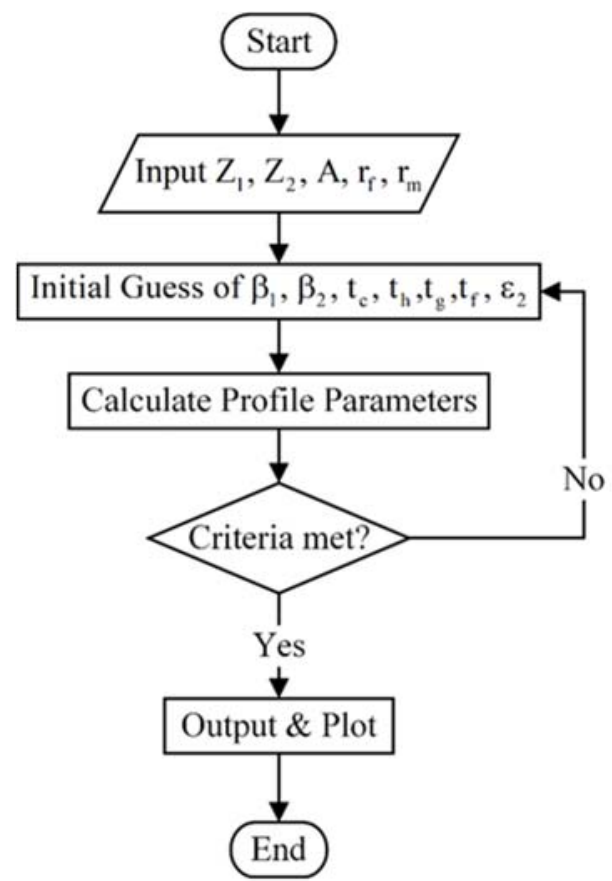

Fig. 2. TSE profile generation flowchart.

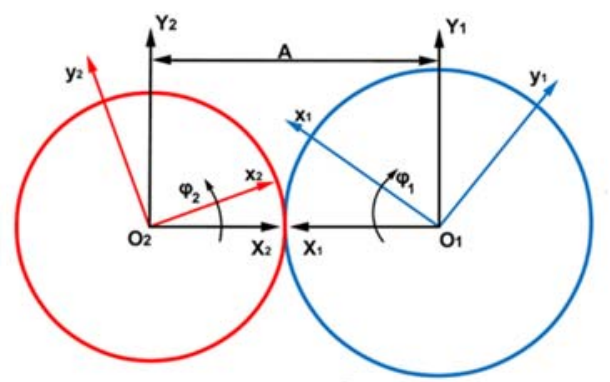

Fig. 3. Coordinate systems of the rotors.

Accordingly, the following relation is defined for rotation angles :

$\mathrm{i}=\frac{\varphi_{2}}{\varphi_{1}}$

Let $\mathrm{k}=\mathrm{i}+1$, the following relationships are derived between the two rotating coordinate systems.

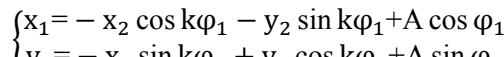




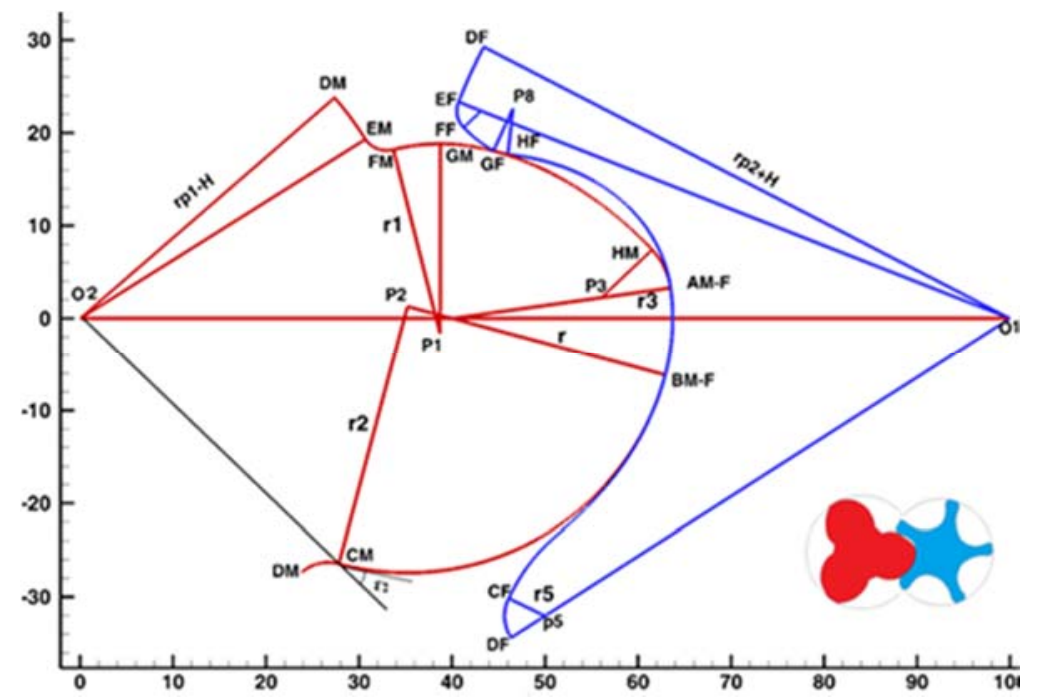

Fig. 4. TSE rotor profile generated by the FORTRAN code.

$\left\{\mathrm{x}_{2}=-\mathrm{x}_{1} \cos \mathrm{k} \varphi_{1}-\mathrm{y}_{1} \sin \mathrm{k} \varphi_{1}+\mathrm{A} \cos \mathrm{i} \varphi_{1}\right.$

$\left\{\mathrm{y}_{2}=-\mathrm{x}_{1} \sin \mathrm{k} \varphi_{1}+\mathrm{y}_{1} \cos \mathrm{k} \varphi_{1}+\mathrm{A} \sin \mathrm{i} \varphi_{1}\right.$

The position vector for the male rotor profile in its coordinate system can be determined by Eq. (4).

$\left\{\mathrm{x}_{2}=\mathrm{x}_{2}(\mathrm{t})\right.$

$\mathrm{y}_{2}=\mathrm{y}_{2}(\mathrm{t})$

Where $t$ stands for the curvature parameter of the male rotor. The locus of the female rotor profile comprising a set of curves in the $\mathrm{O}_{1} \mathrm{X}_{1} \mathrm{Y}_{1}$ coordinate system is specified by:

$\left\{\begin{array}{l}\mathrm{x}_{1}=\mathrm{x}_{1}\left(\mathrm{t} \cdot \varphi_{1}\right) \\ \mathrm{y}_{1}=\mathrm{y}_{1}\left(\mathrm{t} \cdot \varphi_{1}\right)\end{array}\right.$

These sets of curves generate envelopes for various angles, i.e. the curve conjugate of the male rotor. A contact point exists between the generated envelope and each curve wherein there is an identical slope of the curve tangent, given as below in each point of the envelope:

$\frac{\mathrm{dy}_{1}}{\mathrm{dx}_{1}}=\frac{\left(\frac{\partial \mathrm{y}_{1}}{\partial \mathrm{t}}+\frac{\partial \mathrm{y}_{1}}{\partial \varphi_{1}} \cdot \frac{\partial \varphi_{1}}{\partial \mathrm{t}}\right) \mathrm{dt}}{\left(\frac{\partial \mathrm{x}_{1}}{\partial \mathrm{t}}+\frac{\partial \mathrm{x}_{1}}{\partial \varphi_{1}} \cdot \frac{\partial \varphi_{1}}{\partial \mathrm{t}}\right) \mathrm{dt}}$

And the tangent slope at a given point of each set of curves is defined by Eq. (7) once assuming $\varphi_{1}$ to be constant.

$\frac{d y_{1}}{d x_{1}}=\frac{\left(\frac{\partial \mathrm{y}_{1}}{\partial \mathrm{t}}\right) \mathrm{dt}}{\left(\frac{\mathrm{xt}_{1}}{\partial \mathrm{t}}\right) \mathrm{dt}}$

With the assumption of the same slope at each envelope-curve contact point:

$\left|\begin{array}{ll}\frac{\partial \mathrm{x}_{1}}{\partial \mathrm{t}} & \frac{\partial \mathrm{x}_{1}}{\partial \varphi_{1}} \\ \frac{\partial \mathrm{y}_{1}}{\partial \mathrm{t}} & \frac{\partial \mathrm{y}_{1}}{\partial \varphi_{1}}\end{array}\right|=0$

The above determinant is referred as the envelope condition (called interference equation). Also, the male rotor conjugate profile is obtained by determining $\varphi_{1}$ from the interference equation and substituting it in Eq. (3). Each rotor profile comprises eight curved sections (see Fig. 4) with various geometric shapes, namely circles, cycloids, and epicycloids, where they have different parameters describing them on each rotor, including starting and ending angles, center coordinates, radius, and other geometric parameters.

\subsection{Geometry Model and Meshing}

The TSE 3D model includes three major parts, namely inlet port, rotors, and outlet port (see Fig. $5)$.

Unstructured (tetrahedral) grid was used for inlet and outlet ports that were generated by ANSYS ICEM 16.2 whereas structured (hexahedral) grid was applied within the rotors. An in-house code was developed for generation of the grid in nonstationary domains between the two rotors. First, numerical grids were delivered to the solver by the code at each time step, followed by the update of meshes for different rotor positions by the aid of an external subroutine. Figure 6 depicts a fully-meshed rotor cross section.

In 2013, Hutker and Brummer designed and manufactured a laboratory model of TSE in Dortmund, Germany, with $3 / 5$ lobe rotor combination. It was tested as an oil-free machine (air as the working fluid) under different operating conditions. $\mathrm{L} / \mathrm{D}$ was 1.406 and the outer diameters of the male and female rotors were $71.847 \mathrm{~mm}$ and $67.494 \mathrm{~mm}$, respectively. The male rotor wrap angle and the distance between the rotors were $200^{\circ}$ and $51.222 \mathrm{~mm}$, respectively. The designed operating speed of the expander ranges between 2000 and $16000 \mathrm{rpm}$. Hence three rotational speeds of 2000 , 5000 and $10000 \mathrm{rpm}$ were selected as representatives for the simulation process. 


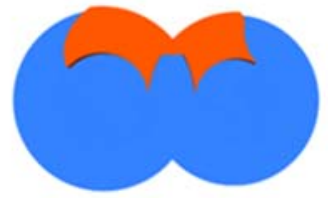

Inlet port

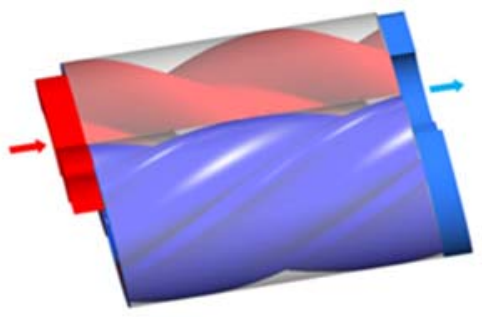

Fig. 5. TSE simulation model.

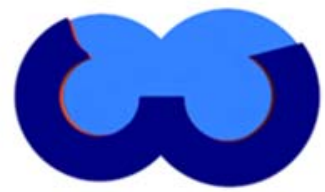

Outlet port

Table 1 Experimental values (Hutker and Brummer , 2013)

\begin{tabular}{|c|c|c|c|c|c|c|}
\hline \multirow{2}{*}{ Speed } & \multicolumn{2}{|c|}{$2000 \mathrm{rpm}$} & \multicolumn{2}{c|}{$5000 \mathrm{rpm}$} & \multicolumn{2}{c|}{$10000 \mathrm{rpm}$} \\
\hline $\begin{array}{c}\text { Pressure } \\
{[\mathrm{bar}]}\end{array}$ & $\begin{array}{c}\text { Flow Rate } \\
{[\mathrm{kg} / \mathrm{s}]}\end{array}$ & $\begin{array}{c}\text { Power } \\
{[\mathrm{w}]}\end{array}$ & $\begin{array}{c}\text { Flow Rate } \\
{[\mathrm{kg} / \mathrm{s}]}\end{array}$ & $\begin{array}{c}\text { Power } \\
{[\mathrm{w}]}\end{array}$ & $\begin{array}{c}\text { Flow Rate } \\
{[\mathrm{kg} / \mathrm{s}]}\end{array}$ & $\begin{array}{c}\text { Power } \\
{[\mathrm{w}]}\end{array}$ \\
\hline 2 & 0.0327 & 758.50 & 0.0511 & 1817.65 & 0.0786 & 3444.82 \\
\hline 3 & 0.0409 & 1492.35 & 0.0737 & 3589.64 & 0.1179 & 7148.29 \\
\hline
\end{tabular}

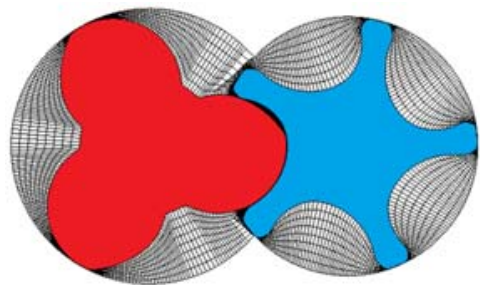

Fig. 6. Meshing between the rotors.

The results of the CFD model proposed in the present study were validated against the experimental data (Table 1) from the former machine.

\subsection{Boundary Condition and Mesh Dependency}

ANSYS CFX a second-order upwind scheme were used for 3D modeling of the TSE and to discretize the governing equations, respectively. SIMPLEC algorithm was implemented as the velocity-pressure fields coupling, and the Spalart-Allmaras turbulence model was selected as the flow turbulence model. Surface roughness was set to smooth for all walls.

Dry air entered the expander under the opening boundary conditions and behavior of ideal gas law with the following specifications: molar mass of $28.96 \mathrm{~kg} / \mathrm{kmol}$, dynamic viscosity of $1.831 \times 10^{-5}$ $\mathrm{kg} / \mathrm{ms}$, specific heat capacity of $1004.4 \mathrm{~J} / \mathrm{kg} . \mathrm{K}$, thermal conductivity of $2.61 \times 10^{-2} \mathrm{~W} / \mathrm{m} . \mathrm{K}$, and pressure of 2.0 bar at $350 \mathrm{~K}$. It left the expander with the pressure of 1.0 bar at $298 \mathrm{~K}$ after being expanded. As per the mesh dependency method proposed by Aqiang et al. (2018), Fig. 7 shows the expander output power at the filling pressure and rotational speed of 2.0 bar and $4000 \mathrm{rpm}$, respectively. As can be observed, the minimum required number of cells is about 568,770 .

\subsection{CFD Model Validation}

Figure 8 compares the experimental data (Hutker and Brummer, 2013) with the simulation expansion curve, indicating good consistency between laboratory model and CFD modeling. As can be seen the figure, the inlet port opens to let high-pressure air in the expander and then the inlet port closes at the angle of $207^{\circ}$, followed by the continual of the expansion process to the angle of $342^{\circ}$ where the outlet port opens to allow the discharge process.

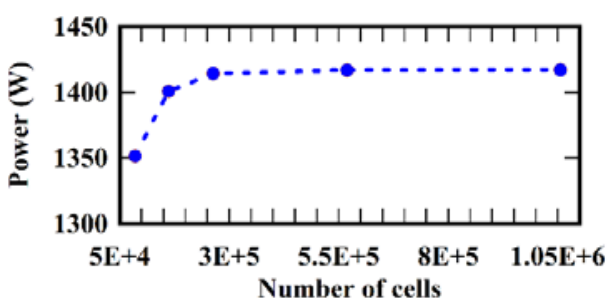

Fig. 7. Mesh dependency of the power.

Based on the torque exerted on the rotors, the TSEgenerated power was calculated at different rotational speeds and compared with laboratory results under the same conditions. According to the simulation results, Figs. 9 and 10 depict the torque exerted on the male and female rotors at different rotational speeds and filling pressure of $2.0 \mathrm{bar}$.

The TSE-produced power is calculated based on the average torque exerted on the rotors for one full rotation (male rotation of $360^{\circ}$ ), i.e. three expansion cycles, as follows:

$P=\frac{2 \pi \mathrm{n} \cdot\left(T_{\text {male }}+\left(\frac{z_{2}}{z_{1}}\right) \cdot T_{\text {female }}\right)}{60} \cdot\left(\eta_{\text {gear }} \cdot \eta_{\text {gen }}\right)$

Where $\mathrm{P}$ and $T$ represent power and torque applied on the rotors, respectively. $n$ denotes the rotational speed of rotor and $z_{1}$ and $z_{2}$ stand for the numbers of lubes of the male and female rotors, respectively. Also, $\eta_{\text {gear }}$ and $\eta_{\text {gen }}$ denote gearbox and generator efficiency, respectively. Marcuccilli (2008) showed that the typical amounts of produced power lost in the gearbox and generator are about $1.5-2 \%$ and $2-$ $5 \%$, respectively. Table 2 lists the results of the CFD 
H. Abolhasani et al. / JAFM, Vol. 13, No. 4, pp. 1179-1191, 2020.

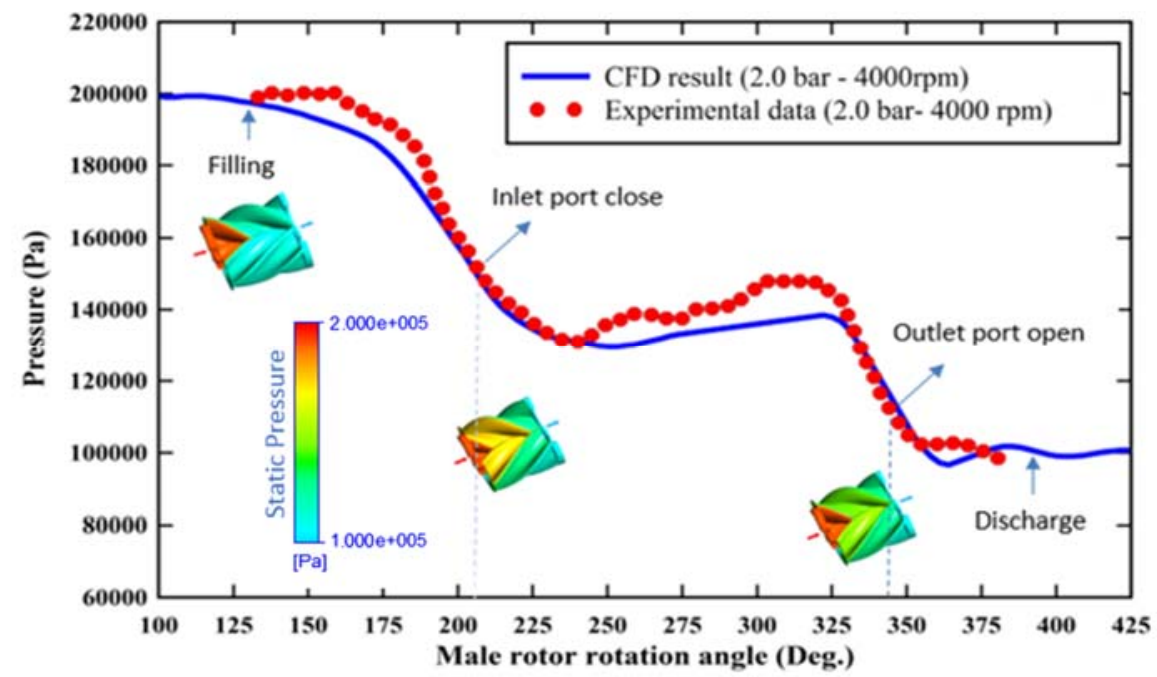

Fig. 8. Operating cycle of a TSE.

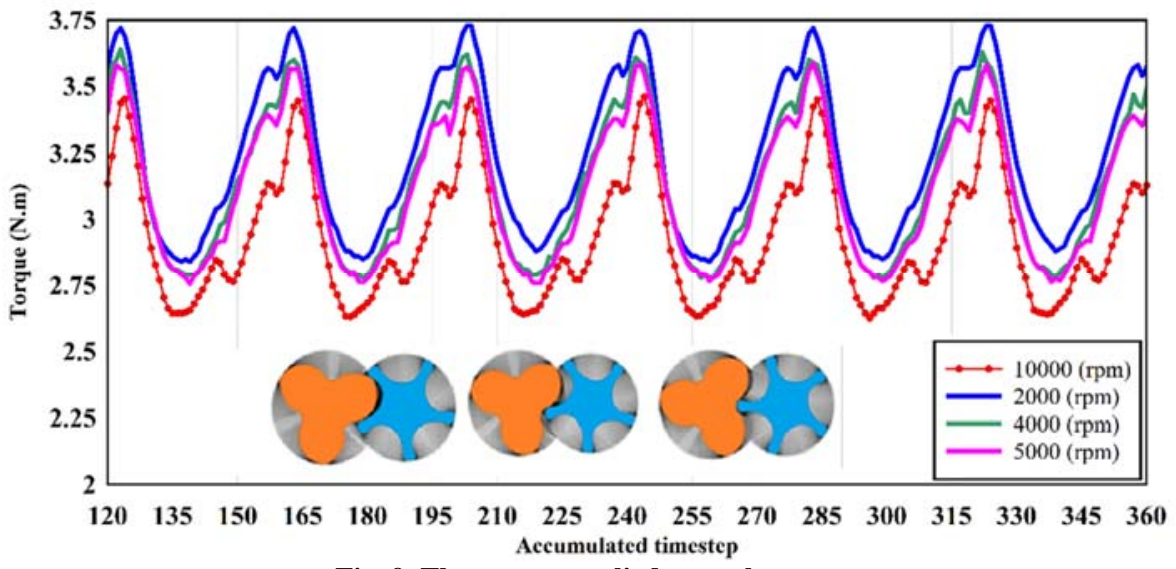

Fig. 9. The torque applied on male rotor.

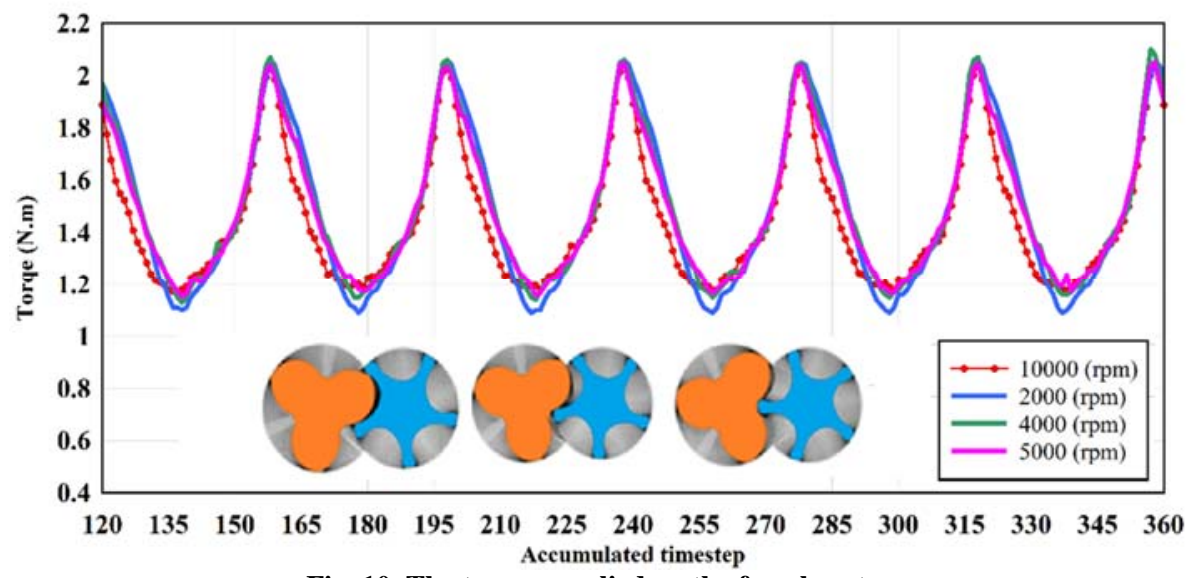

Fig. 10. The torque applied on the female rotor.

model under similar conditions to the laboratory model.

Figure 11 provides a comparison between the power calculated by the CFD model and the experimental data at different rotational speeds and two inlet pressures. As can be observed, the CFD model accurately estimated the performance of the laboratory model. 
H. Abolhasani et al. / JAFM, Vol. 13, No. 4, pp. 1179-1191, 2020.

Table 2 CFD modeling results

\begin{tabular}{|c|c|c|c|c|c|c|}
\hline Speed & \multicolumn{2}{|c|}{$2000 \mathrm{rpm}$} & \multicolumn{2}{c|}{$5000 \mathrm{rpm}$} & \multicolumn{2}{c|}{$10000 \mathrm{rpm}$} \\
\hline $\begin{array}{c}\text { Pressure } \\
{[\mathrm{bar}]}\end{array}$ & $\begin{array}{c}\text { Flow Rate } \\
{[\mathrm{kg} / \mathrm{s}]}\end{array}$ & $\begin{array}{c}\text { Power } \\
{[\mathrm{w}]}\end{array}$ & $\begin{array}{c}\text { Flow Rate } \\
{[\mathrm{kg} / \mathrm{s}]}\end{array}$ & $\begin{array}{c}\text { Power } \\
{[\mathrm{w}]}\end{array}$ & $\begin{array}{c}\text { Flow Rate } \\
{[\mathrm{kg} / \mathrm{s}]}\end{array}$ & $\begin{array}{c}\text { Power } \\
{[\mathrm{w}]}\end{array}$ \\
\hline 2 & 0.0327 & 720.9 & 0.0492 & 1761.54 & 0.075 & 3363.9 \\
\hline 3 & 0.0504 & 1515.6 & 0.0742 & 3797.3 & 0.114 & 7376.9 \\
\hline
\end{tabular}

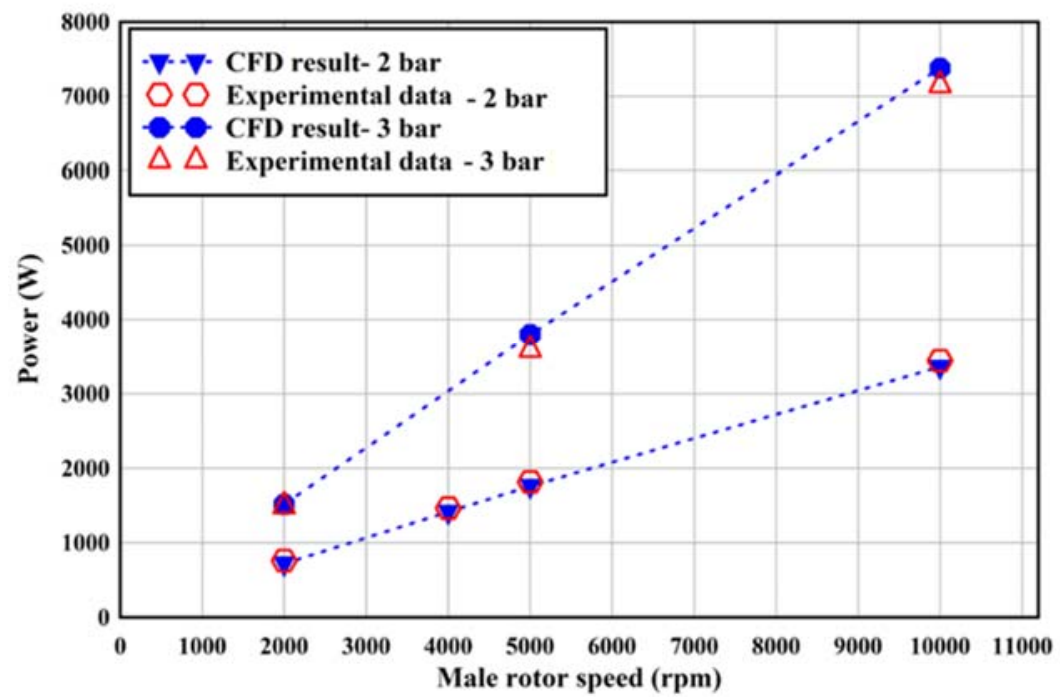

Fig. 11. Power vs. rotational speed at different pressures.

Table 3 Specific power results

\begin{tabular}{|c|c|c|c|c|c|c|}
\hline Speed & $2000(\mathrm{rpm})$ & \multicolumn{2}{c|}{$5000(\mathrm{rpm})$} & \multicolumn{2}{c|}{$10000(\mathrm{rpm})$} \\
\hline \multirow{3}{*}{ Pressure } & \multicolumn{2}{|c|}{$\begin{array}{c}\text { Specific Power } \\
(\mathrm{kW} / \mathrm{kg} / \mathrm{s})\end{array}$} & \multicolumn{2}{c|}{$\begin{array}{c}\text { Specific Power } \\
(\mathrm{kW} / \mathrm{kg} / \mathrm{s})\end{array}$} & \multicolumn{2}{c|}{$\begin{array}{c}\text { Specific Power } \\
(\mathrm{kW} / \mathrm{kg} / \mathrm{s})\end{array}$} \\
\cline { 2 - 7 } & $\begin{array}{c}\text { Experimental } \\
\text { data }\end{array}$ & $\begin{array}{c}\text { CFD } \\
\text { results }\end{array}$ & Experimental data & $\begin{array}{c}\text { CFD } \\
\text { results }\end{array}$ & Experimental data & $\begin{array}{c}\text { CFD } \\
\text { results }\end{array}$ \\
\hline 2.0 (bar) & 23.1957 & 22.0459 & 35.5705 & 35.8037 & 43.8272 & 44.8520 \\
\hline 3.0 (bar) & 36.4878 & 30.0714 & 48.7061 & 51.1765 & 60.6301 & 64.7096 \\
\hline
\end{tabular}

Table 4 CFD modeling results (2000 rpm, 3.0 bar)

\begin{tabular}{|c|c|c|c|c|}
\hline Case & Turbulence model & Mass flow $(\mathrm{kg} / \mathrm{s})$ & Power $(\mathrm{kW})$ & $\begin{array}{c}\text { Specific Power } \\
(\mathrm{kW} / \mathrm{kg} / \mathrm{s})\end{array}$ \\
\hline Experiment & - & 0.0409 & 1.4924 & 36.4878 \\
\hline Case 1 (CFD) & SSG-Reynolds & 0.0571 & 1.4997 & 26.2638 \\
\hline Case 2 (CFD) & SST+Curvature Correction & 0.0573 & 1.5089 & 26.3329 \\
\hline Case 3 (CFD) & Spalart -Allmaras & 0.0504 & 1.5156 & 30.0714 \\
\hline Case 4 (CFD) & K-Omega & 0.0552 & 1.5090 & 27.3370 \\
\hline
\end{tabular}

Specific power is defined as the ratio of the indicated power to the mass flowrate through the TSE, which is a criterion for evaluating the consistency of all the parameters expressed for the CFD model with those of the experimental model. In other words, a specific power closer to the experimental model indicates a better simulation. Table 3 compares specific power between the CFD model and experimental data. As can be seen in the table, aside from low speed and high pressures conditions ( 3 bar, $2000 \mathrm{rpm}$, respectively), the CFD model acceptably estimated the accuracy and performance of the laboratory model.

Table 4 lists the CFD modelling results using different turbulence models at the rotational speed and filling pressure of $2000 \mathrm{rpm}$ and $3.0 \mathrm{bar}$, respectively, in comparison to the experimental data. 


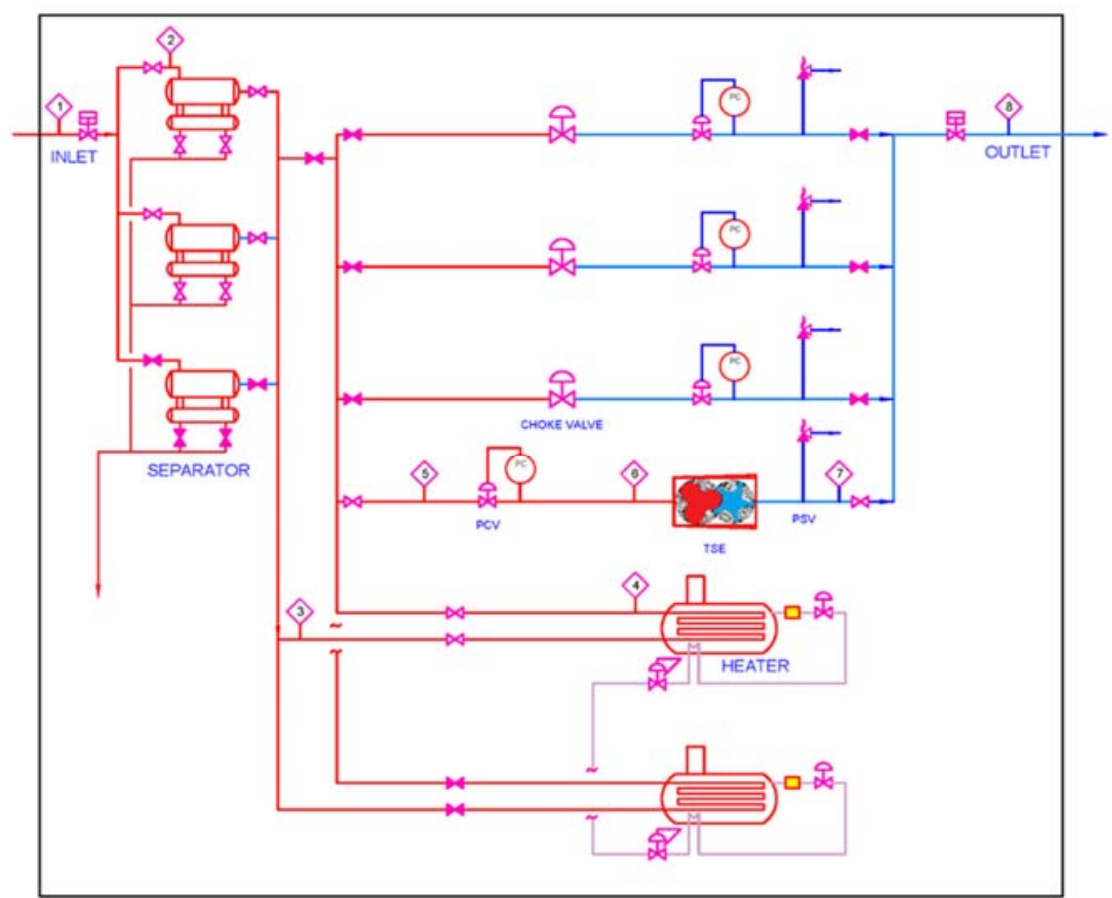

Fig. 12. General schematic view of TSE utilization at Shahroud CGS.

As can be observed, the mass flow rate values using the Spalart-Allmaras turbulence model are accurate at low pressure but are over estimated at low speed and high pressure (2000 rpm , 3.0 bar, respectively) where the leakage is higher (Kovacevic and Rane, 2013). Therefore, other turbulence models were found to achieve better simulation of the TSE in this regime.

The results showed that the Spalart-Allmaras turbulence model is the most suitable choice for the TSE simulation since it estimated the specific power closer to the experimental data.

\section{SHAHROUD CGS}

Figure 12 shows the general schematic view of the CGS station and proposed design for utilization of the TSE. As can be observed, gas is heated at the entrance of the expander after passing through a separator up to the required temperature and then pressurized by the TSE to the desired value. A pressure control valve (PCV) was installed at the expander inlet to control the inlet pressure. Natural gas (NG) enters the TSE with the composition listed in Table 5 under variable process conditions (point $6)$.

The inlet pressure and temperature of the expander vary from day to day based on the $\log$ sheets registered at the station. Figures 13 and 14 show the pressure and temperature fluctuations on a daily basis over the year, respectively. The outlet flow of the TSE at point 7 needs to guarantee a constant pressure of $250 \mathrm{psig}$.

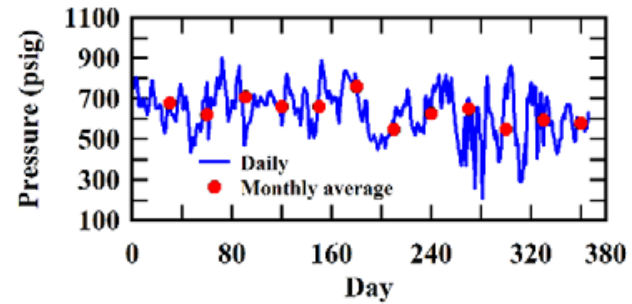

Fig. 13. Pressure daily variations.

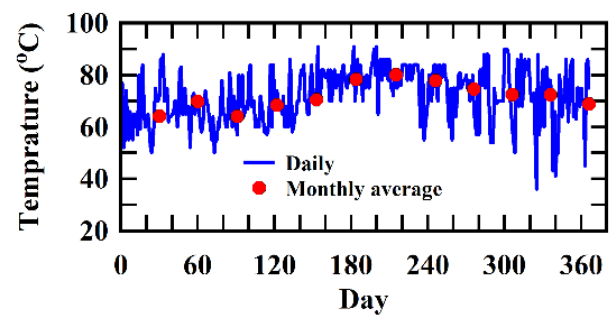

Fig. 14. Temperature daily variations.

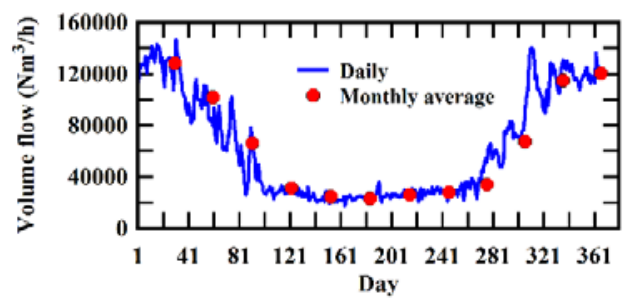

Fig. 15. Daily variations of inlet gas flow. 


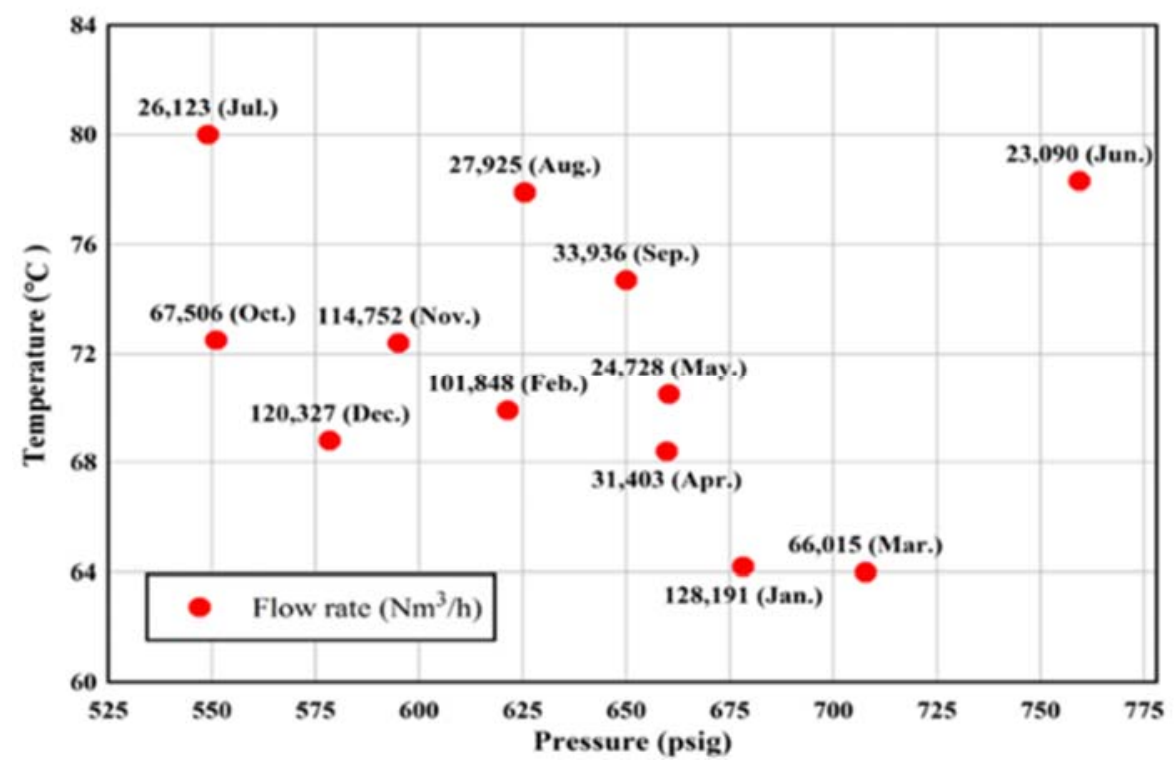

Fig. 16. NG monthly average process parameters.

Table 5 Natural gas composition

\begin{tabular}{|c|c|}
\hline Component & Mole Fraction (\%) \\
\hline $\mathrm{N}_{2}$ & 2.49 \\
\hline $\mathrm{CO}_{2}$ & 1.8 \\
\hline $\mathrm{CH}_{4}$ & 89 \\
\hline $\mathrm{C}_{2} \mathrm{H}_{6}$ & 4.86 \\
\hline $\mathrm{C}_{3} \mathrm{H}_{8}$ & 1.2 \\
\hline $\mathrm{i}-\mathrm{C}_{4} \mathrm{H}_{10}$ & 0.22 \\
\hline $\mathrm{n}-\mathrm{C}_{4} \mathrm{H}_{10}$ & 0.23 \\
\hline $\mathrm{i}-\mathrm{C}_{5} \mathrm{H}_{12}$ & 0.1 \\
\hline $\mathrm{n}-\mathrm{C}_{5} \mathrm{H}_{12}$ & 0.1 \\
\hline
\end{tabular}

Table 6 Shahroud TSE specifications required

\begin{tabular}{|c|c|c|}
\hline Parameter & Value & Unit \\
\hline Female number of lobes, Z1 & 5 & - \\
\hline Male number of lobes, Z2 & 3 & - \\
\hline Distance of the rotors, A & 255 & $\mathrm{~mm}$ \\
\hline Male rotor wrap angle, $\boldsymbol{\Psi}$ & 200 & degree \\
\hline Male rotor outer diameter, D & 360 & $\mathrm{~mm}$ \\
\hline L/D & 1.406 & - \\
\hline
\end{tabular}

Gas flow rate changes at the CGS station are among the most important factors that should be incorporated into the process of using an expansion turbine. It considerably varies over different seasons of the year, especially in winter where energy demand is high (as shown in Fig.15)

Figure 16 shows the monthly average values of process parameters for predicting the TSE performance based on the variable input conditions (Figs. 13-15).

The already-validated CFD model was scaled-up to cover the annual mean flow passing through the station, which has been assumed as the design point. Accordingly, the overall dimensions and main characteristics of the TSE required at Shahroud station were specified (as shown in Table 6).

Now, the performance curve of the TSE is obtained by using of the exergy analysis based on the above TSE model and average process parameters.

\section{EXERGy ANALYSIS}

The sink and source method was implemented to calculate exergy efficiency. The gas flow and the net axial work were assumed as the exergy source and sink, respectively. The available exergy can be written as;

$$
\begin{aligned}
& \Delta E X_{\text {source }}=n \cdot R \cdot \mathrm{T}_{0} \cdot \operatorname{Ln}\left(\frac{P_{1}}{P_{2}}\right)+ \\
& \dot{m} \cdot\left(h_{1}-h_{2}\right)\left(1-\left(\frac{\mathrm{T}_{0}}{\mathrm{~T}_{1}-\mathrm{T}_{2}}\right) \operatorname{Ln}\left(\frac{\mathrm{T}_{1}}{\mathrm{~T}_{2}}\right)\right)
\end{aligned}
$$

Where $n$ represents the number of moles of gas, $R$ indicates universal gas constant, $T_{0}$ stands for the ambient temperature, $P_{1}$ and $P_{2}$ are inlet and outlet pressures, respectively, $\dot{m}$ represents the mass flow rate, $h$ denotes specific enthalpy, and $T$ is temperature. The net expander power was calculated as the exergy sink from Eq. (9).

Finally, the exergy efficiency is calculated by Eq. (11).

$$
\eta_{E x}=\frac{P}{\Delta E X_{\text {source }}}
$$

Figure 17 depict the dimensionless TSE performance curve based on the CFD simulation results for different months of the year.

According to the performance curve, if the flow rate of the TSE is less than that at the design point (annual average), then the expander efficiency decreases. In 


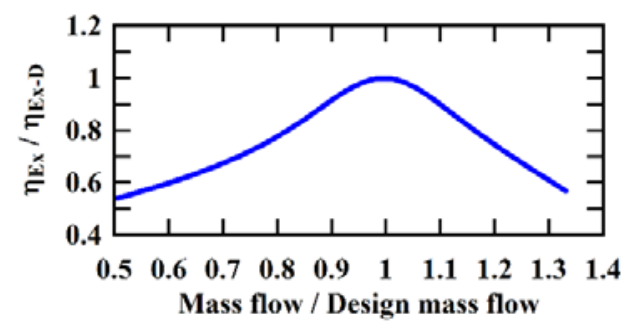

Fig. 17. TSE performance curve in Shahroud CGS.

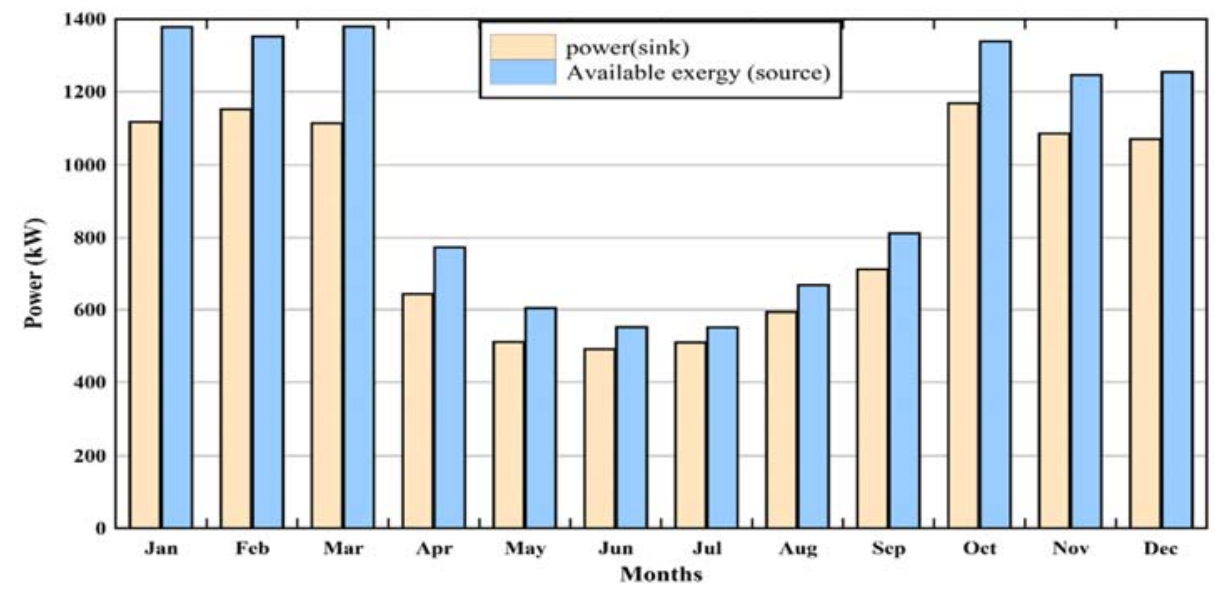

Fig. 18. The power generated by TSE vs. available exergy.

other words, if the expander works out of the design point, its efficiency is reduced due to over-load depreciations. Therefore, the maximum efficiency of the expander is obtained when the entire flow passes through the TSE and the choke valve acts as a standby. Accordingly, the annual performance of the TSE is shown in Fig. 18

The expander operates at its maximum working capacity in winter and spring due to the high-energy demand days. In other months of the year, the expander performance is lower than the design capacity and, in turn, the TSE production capacity declines as well. The previous studies have shown that the use of CET in some months of the year, especially hot months, is not feasible due to the fluctuations in flow and pressure when even the expander efficiency drops below $70 \%$. In addition, due to the high gas flowrate in the CGS stations, the corresponding model for their use in these stations should be addressed (Fig. 19), which increases their investment cost. However, based on the results of the CFD simulation, this limitation does not exist for the TSE.

\section{ECONOMIC ANALYSIS}

The results of TSE simulation showed that the maximum available annual recoverable exergy at the Shahroud station is $8,719,859 \mathrm{kWh}$. Figure 20 illustrates power loss for each month of the year versus the maximum recoverable exergy.
Accordingly, the effective exergy of about 7,438,279 $\mathrm{kWh}$ can be annually recovered by the TSE which is denoted by $P_{0}$ in Eq. (12). This is necessary to calculate the annual revenue of the TSE.

Since the power generation is obtained by the pressure drop in the CGS, the generated electricity is a clean source with a net zero carbon footprint. Therefore, the expected cost in this field includes the initial investment, annual operation costs, and maintenance costs. Based on the available information (Rattler Energy, 2019), the initial investment cost for a TSE is about $2000 \$ / \mathrm{kW}$ and it needs to be overhauled after 50,000 hours or approximately five years of operation. Furthermore, the annual operation and maintenance costs equals 0.25 cents $/ \mathrm{kW}$.

The highest production capacity of the expander is achieved in October (i.e. 1,167 kW) and, therefore, the TSE's capital cost (CP) will be 2,334,000 \$. Also, let the electricity price be 6 cents/kWh (FarzanehKord et al. 2016) as, the annual value of the electricity produced by the TSE is calculated by Eq. (12).

$$
B_{n}=P_{0} * S_{1} *(1+i)^{n-1}
$$

Where $B_{n}$ is the annual value of generated electricity $(\$), P_{0}$ indicates the annual production power of the expander $(\mathrm{kWh}), S_{1}$ denotes the unit price of generated electricity $(\$ / \mathrm{kWh}), i$ represents the discount rate, and $n$ is the number of time periods. 


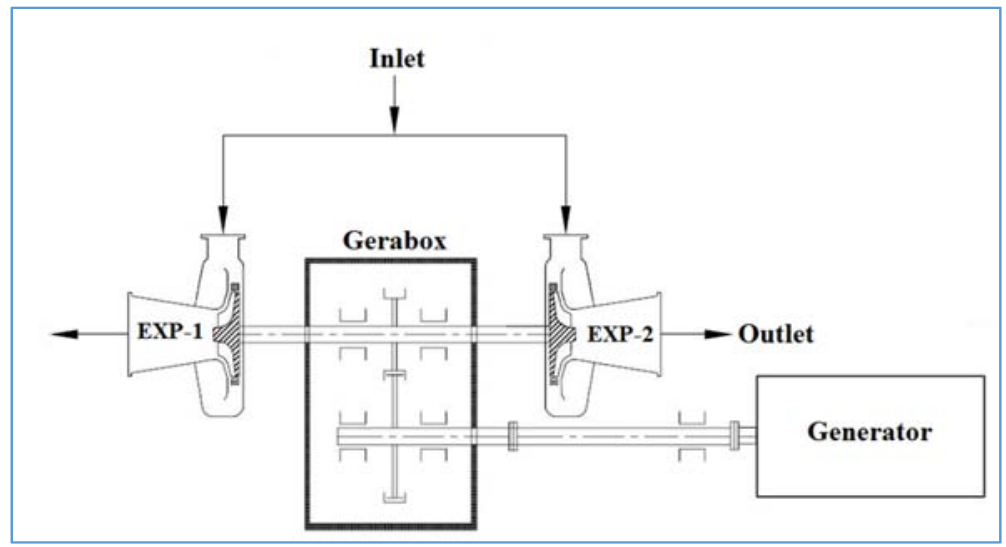

Fig. 19. The CET modeling.

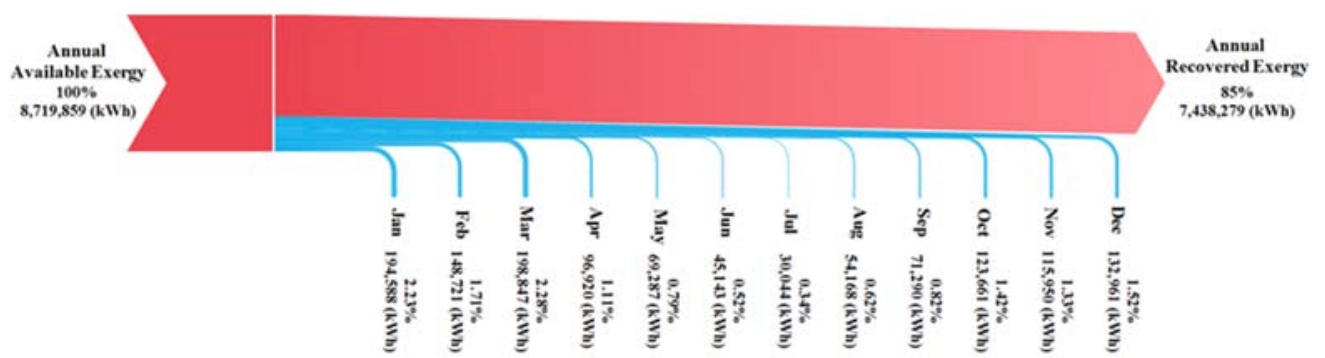

Fig. 20. Grassman diagram of monthly exergy destruction.

The present value of the receivables is equal to the current investment value at the internal rate of return (IRR). Thus, the net present value is zero (Kocaaslan et al. 2016) based on Eq. (13)

$$
\sum_{n=1}^{20} \frac{B_{n}-\Sigma(\operatorname{Cos} t)_{n}}{(1+I R R)^{n}}-C P=0
$$

Payback period is defined as the required time to recover the investment and is obtained from Eq. (14).

$$
\sum_{n=1}^{n} \frac{B_{n}-\Sigma(\operatorname{Cost})_{n}}{(1+i)^{n}}+\frac{S V}{(1+i)^{20}}-C P=0
$$

Where $S V$ is the salvage value of turbo expander after 20 years, i.e. equivalent to $30 \%$ of the initial investment in the twentieth year.

Let the capital cost of CET be $40 \%$ higher than TSE on average (Rattler Energy, 2019) and their operation and maintenance costs be $2 \%$ of their capital cost (Ghasemikafrudi et al. 2017), Table 7 provides an economic comparison between the TSE and CET at the same annual produced power.

Table 7 TSE and CET economic comparison

\begin{tabular}{|c|c|c|}
\hline Proposed systems & $\begin{array}{c}\text { Payback period } \\
\text { (year) }\end{array}$ & IRR (\%) \\
\hline TSE & 4.4 & 27.6 \\
\hline CET & 7.5 & 17.5 \\
\hline
\end{tabular}

According to the table, using a CET at Shahroud station (a medium station) is economically unjustifiable since the payback period and the IRR factor for TSE are considerably better than that of the CET. This indicates that the TSE is much more economical than the common expansion turbine at the CGS stations. The main challenge in screw machines is their internal leakages which can be minimizes by an optimized design of the machine. However, the results of this study showed that, compared to the CET, the use of the TSE at the CGS stations to recover lost exergy is so technically and economically attractive that it would marginalize the problem of internal leakages in TSEs.

\section{Conclusion}

This study aimed at performing a technical and economic analysis of a TSE as an alternative parallel to the choke valves at a CGS to generate electrical power. This is because the gas pressure reduction process achieved through choke valves at the CGS results in $100 \%$ loss of the useful exergy. Although several studies have been conducted in this regard, the use of CETs has been currently limited due to serious issues such as high installation cost, long payback period, high cost of operation and maintenance, and pressure and flowrate fluctuations,. However, the TSE offers a significant advantage over the CET and is economically approved to be used in CGS. Hence, in this study, a TSE profile with $3 / 5$ lobe rotor combination was designed using envelope theory and incorporating an 
in-house developed code into FORTRAN. Also, its performance was evaluated by the three-dimensional CFD simulation compared to an existing laboratory model. The 3D simulation results based on the Spalart-Allmaras turbulence model agreed well with the experimental data. After the scale-up process, the TSE performance was analyzed under pressure and mass flowrate fluctuations. The results revealed that, unlike CET, the performance of the TSE was completely stable under variable process conditions and, in turn, it can be used during all months of the year to recover lost exergy at the CGS stations. The results of technical studies at Shahroud CGS indicated that the exergy loss has been recovered by about $85.3 \%$ using a TSE in the variable process condition. Furthermore, the internal rate of return obtained of $27.6 \%$ suggested the suitability of the proposed economic plan. Therefore, by comparing the technical and economic aspects of the TSE and CET, it can be concluded that the TSE has outperformed the CET in terms of generating electrical power at the CGS stations.

\section{REFERENCES}

Andres, R., J. Hesse, H. Babic, U. Salecker, A. Spille-Kohoff, A. Nikolov and A. Bruemmer (2016, July). CFD simulation of a twin screw expander including leakage flows. International Compressor Engineering Conference 2497, Purdue University.

Aqiang, L., S. Yonggang, Z. Hai, L. Xiang, Y. Lu and Z. Qun (2018). Fluctuating characteristics of air-mist mixture flow with conjugate wallfilm motion in a compressor of gas turbine. Journal of Applied Thermal Engineering 142, 779-792.

Brummer, A. and J. Hutker (2009). Influence of geometric parameters on inlet losses during the filling process of screw-type motors. Developments in Mechanical Engineering 4, 105-121.

Diao, A., Y. Wang, Y. Guo and M. Feng (2018). Development and application of screw expander in natural gas pressure energy recovery at city gas station. Journal of Applied Thermal Engineering 142, 665-673.

Domingues, N. S. (2018). Screw Expander for Energy Production in Natural Gas Pressure Reduction and Mesurement Stations. Recent Advances in Petrochemical Science 4, 1-5.

El Hadik, A. A. (1990). The Impact of Atmospheric Conditions on Gas Turbine Performance. Transactions of the American Society of Mechanical Engineers 112, 590-596.

Farzaneh-Kord, V., A. B. Khoshnevis, A. Arabkoohsar, M. Deymi-Dashtebayaz, M. Aghili, M. Khatib and M. Kargaran (2016). Defining a technical criterion for economic justification of employing CHP technology in city gate stations. Journal of Energy 111, 389401 .
Ghasemikafrudi, E., S. Yousefi and F. G. Chegini (2017). Environmental study of waste energy recovery by using exergy and economic analysis in a fluid catalytic cracking unit. Advance in environmental technology 4,229 242

Graber, M. and A. Brummer (2015, September). Influence of liquid in clearances on the operational behaviour of twin screw expanders. 9th International Conference on Compressors and their Systems, 12060, City University London.

Howard, C., P. Oosthuizen and B. Peppley ( 2011). An investigation of the performance of a hybrid turboexpander-fuel cell system for power recovery at natural gas pressure reduction stations. Journal of Applied Thermal Engineering 31, 2165-2170.

Hutker, J. and A. Brummer (2013, September). Physics of a dry running unsynchronized twin screw expander. 8th International Conference on Compressors and Their Systems, 407-416, City University London.

Hutker, J. and A. Brummer (2012, July). Thermodynamic design of screw motors for constant waste heat flow at medium temperature level. International Compressor Engineering Conference 1478, Purdue University.

Kocaaslan, O., M. Ozgoren, M. H. Aksoy and O. Babayigit (2016). Experimental and numerical investigation of coating effect on pump impeller and volute. Journal of Applied Fluid Mechanics 9 (5), 2475-2487.

Kovacevic, A. and S. Rane (2013, September). 3D CFD analysis of a twin screw expander. 8th International Conference on Compressors and their Systems, 417-429, City University London.

Marcuccilli, F. (2008). Advantages of using radial inflow turbines for kalina and organic rankine cycles. GRC Transactions 32, 413-418.

Nikolov, A., C. Huck and B. Andreas ( 2012, July). Influence of thermal deformation on the characteristic diagram of a screw expander in the automotive application of exhaust heat recovery. International Compressor Engineering Conference, 2128, Purdue university.

Olfati, M., M. Bahiraei, S. Heidari and F. Veysi ( 2018). A comprehensive analysis of energy and exergy characteristics for a natural gas city gate station considering seasonal variations. Journal of Energy 155, 721-733.

Papes, I., J. Degroote and J. Vierendeels ( 2014, July). 3D CFD analysis of a twin screw expander for small scale ORC systems. 11th World Congress on Computational Mechanics (WCCM XI - 2014), Barcelona, Spain, 72077217. 
H. Abolhasani et al. / JAFM, Vol. 13, No. 4, pp. 1179-1191, 2020.

Pozivil, J. (2004). Use of expansion turbines in natural gas pressure reduction stations. Acta Montanistica Slovaca 9, 258-260.

Rahman, M. M. ( 2010). Power generation from pressure reduction in the natural gas supply chain in Bangladesh. Journal of Mechanic 41, 89-95.

RattlerEnergy,http://www.rattlerenergy.com/total_fl ow generator/advantages.html (accessed 09.06.2019)

Sangfors, B.(1982). Analytical modeling of helical screw machine for analysis and performance prediction $100,482-487$.

Smith, I. K. (1993). Development of the trilateral flash cycle system: Part 1: Fundamental considerations. Proceedings of the Institution of Mechanical Engineers, Part A: Journal of Power and Energy 207, 179-194.

Smith, I. K., N. Stosic and C. A. Aldis (1996). Development of the trilateral flash cycle system: Part 3: The design of high-efficiency two-phase screw expanders. Proceedings of the Institution of Mechanical Engineers, Part A: Journal of Power and Energy 210, 75-93.

Smith, I. K., N. Stosic, C. A. Aldis and A. Kovacevic (1999, September). Twin screw two - phase expanders in large chiller units. International conference on compressors and their systems 105-114, Purdue University.

Smith, Ian K., N. Stosic and A. Kovacevic (2005). Screw expanders increase output and decrease the cost of geothermal binary power plant systems. Transactions - Geothermal Resources Council 29, 787-794.

Smith, I. K., N. Stosic and A. Kovacevic (2005,
April). An improved system for power recovery from higher enthalpy liquid dominated fields. Proceedings World Geothermal Congress Antalya, Turkey.

Steidel, R. F., D. H. Pankow and K. A. Brown (1983). The empirical modeling of a lysholm screw expander. intersociety energy conversion engineering conference, Orlando, U.S.A.

Stosic, N., I. K. Smith and A. Kovacevic (2002). A twin screw combined compressor and expander for $\mathrm{CO} 2$ refrigeration systems. International Compressor Engineering Conference. 1591, Purdue University.

Taheri, R., H. Khodaei and B. Rashidian (2010, July). Retrofit of Tehran city gate station by using turboexpander. Proceedings of the ASME 2010 power conference, Chicago, USA

Tian, Y., Z. Xing, Z. He and H. Wu (2017). Modeling and performance analysis of twin-screw steam expander under fluctuating operating conditions in steam pipeline pressure energy recovery applications. Journal of Energy 141, 692-701.

Zabihi, A. and M. Taghizadeh (2016). Feasibility study on energy recovery at Sari-Akand city gate station using turboexpander. Journal of Natural Gas Science and Engineering 35, 152 159.

Zehtabiyan, R. and N. Saffar (2012, June). Feasibility study of turbo expander installation in city gate station. The 25th International Conference on Efficiency, Cost, Optimization and Simulation of Energy Conversion Systems and Processes , Perugia, Italy, 26-29. 